\title{
El Recreo, tribuna pública de mujeres pioneras en la educación y el periodismo en el Perú del siglo XIX
}

\author{
El Recreo, public tribune Women pioneers in education \\ and journalism in the XIX century \\ Carolina Ortiz Fernández \\ Universidad Nacional Mayor de San Marcos, Lima, Perú \\ Contacto: cortizf@unmsm.edu.pe \\ https://orcid.org/0000-0002-6464-4652
}

\section{Resumen}

En este artículo se explora la performance de las mujeres pioneras en la tribuna pública en el sur del Perú a través de la revista El recreo, la primera de esta región, fundada y dirigida en 1876 por una mujer, la escritora cuzqueña Clorinda Matto de Turner. En la primera parte se realiza una revisión panorámica de las principales publicaciones efectuadas durante los primeros años de la República; seguidamente, se precisan algunos rasgos principales de la trayectoria periodística de Matto de Turner; en la tercera, se explora y expone el propósito de la publicación. Se concluye señalando que Clorinda Matto, Trinidad Enríquez y Mercedes Cabello incursionaron en los espacios públicos de comunicación y saber considerados masculinos; así, propiciaron y defendieron —en el sur del país - la educación de las mujeres y un periodismo alternativo abierto a los intereses sociales y no a los grupos de poder, en un contexto totalmente adverso, por lo que tuvieron que afrontar furibundos ataques de los grupos que temían perder sus privilegios.

Palabras clave: Women; Siglo XIX; Educación; Periodismo; Clorinda Matto de Turner; Trinidad Enríquez; Mercedes Cabello de Carbonera.

\begin{abstract}
This article explores the women 's proposal in the magazine El recreo, founded and directed by Clorinda Matto de Turner in 1876. In the first part, an overview of the very first publications during the early years of the Republic is developed. Following to the next part are the main features of Matto de Turner's journalistic career, and in the third one, the purpose of the publication is explored. It is demonstrated that Clorinda Matto de Turner, Trinidad Enriquez, Mercedes Cabello took the reins of the public spaces of communication and knowledge, to propitiate and defend women's education and an independent journalism, and they were facing furious attacks of power groups that feared losing their privileges
\end{abstract}

Keywords: Women, 19th century; Education, Journalism; Clorinda Matto de Turner; Trinidad Enríquez; Mercedes Cabello de Carbonera. 


\section{Introducción}

Clorinda Matto de Turner, Trinidad Enríquez y Mercedes Cabello —en el sur del país - fueron pioneras en exigir y defender la educación de las mujeres y en promover un periodismo alternativo, abierto a los intereses sociales de las mayorías en el Perú republicano a fines del siglo XIX. Ellas incursionaron en los espacios públicos de comunicación y saber, considerados eminentemente masculinos, en tanto educadoras y redactoras o directoras de algunos semanarios surgidos en el país junto a otras talentosas creadoras, tales como Juana Manuela Gorriti, entre muchas más.

Estas pioneras tuvieron que afrontar furibundos ataques que provenían de los grupos de poder económico, político y patriarcal por atreverse a quebrantar el orden social. Ellas lucharon por su autonomía y la de los medios de comunicación que fundaron, oscilaron entre la ciudad letrada y la ciudad real, no permitieron someterse al sensacionalismo, defendieron la libertad de expresión, los derechos civiles, la educación de las mujeres y de toda la población. Por eso, en esta ocasión exploro la revista El Recreo $^{1}$, publicada en Cuzco entre 1876 y 1877 a iniciativa de Clorinda Matto y dirigida por ella.

\section{Primeras publicaciones en la República}

Según referencias de Raúl Porras Barrenechea (1970), la primera imprenta llegó al Perú en 1584; año en que Antonio Ricardo imprimió el primer libro en Lima y en Sudamérica. Al Cuzco arribó en 1821.

Cuando Lima fue ocupada por los patriotas, el virrey La Serna se instaló en tierra cuzqueña en representación del gobierno realista y dispuso la publicación de la Gaceta del gobierno legítimo del Perú, de 1822 a 1824, mediante la cual difundió que su administración constituía la afirmación del liberalismo hispánico conducente al progreso. En la práctica estuvo muy lejos del ideario liberal, puesto que se opuso a la libertad de expresión; solo permitió la publicación de El Depositario, del realista Gaspar Rico, que se encargó de editar panfletos contra los patriotas y, junto a la Gaceta del gobierno, publicó edictos reales y normas militares. 
A partir de 1824, las gacetas empleadas por los gobiernos coloniales desaparecieron en Sudamérica; en su lugar comenzaron a surgir los periódicos y revistas, tribuna pública eminentemente masculina, que rápidamente se convirtió en formadora de la opinión pública. Los folletines fueron incorporados por estos medios de comunicación y contribuyeron a cultivar el hábito de la lectura. En una primera época fueron secciones fijas, cuyos textos circularon a manera de entrega por partes que concluía con un consabido "continuará”, creando así expectativa para el próximo número. En El Recreo se aprecia esta modalidad en varias secciones dedicadas a la historia, a la reflexión ensayística, al relato y a las tradiciones y leyendas.

El Sol del Cuzco, de tendencia republicana, fue impulsado por el cuzqueño Agustín Gamarra y publicado entre 1825 y 1829. Ramón Matto —padre de Clorinda Matto Usandivaras - y Benito Laso fueron algunos de sus principales redactores. El Censor Eclesiástico dirigido por Laso tuvo corta duración, solo alcanzó a publicar el prospecto y el primer número. Se le recuerda porque tuvo un claro carácter anticlerical y cuestionó los privilegios económicos y políticos de la Iglesia. Laso planteó la inexistencia de una fracción social dirigente debidamente capacitada, por lo que la independencia se había logrado por el empeño de ejércitos foráneos. Estuvo a favor de que Bolívar impusiera el orden público.

La Minerva del Cuzco tuvo como editor a Francisco Mariano de Miranda y Vengoa, y fue publicada entre 1829 y 1834; esta revista, junto con El Sol del Cuzco, apoyó la constitución de la República. Con ese propósito, incentivaron la fiscalización de las instituciones y de las autoridades. Como se sabe, con el triunfo de las fuerzas patriotas, en 1825 llegó al Cuzco Simón Bolívar, quien interesado en la educación dispuso la fundación del Colegio Nacional de Ciencias y del Colegio Nacional de Educandas Nuestra Señora de las Mercedes. Este último fue el primer colegio para mujeres en todo el país que poco después de su inauguración fue clausurado y reabrió sus puertas recién en 1848 .

A partir de entonces surgieron numerosos periódicos y se publicaron libros con una visión incaísta; ello con el interés de comprender y difundir la vida 
cotidiana en Cuzco, sobretodo en torno a la educación y la cultura. Entre 1837 y 1839 se publicó Museo Erudito o Los Tiempos y las Costumbres. Esta revista difundió la realidad europea y americana y por primera vez publicó, según referencias de Tamayo Herrera (1978), el drama Ollantay y diversos artículos con temas alusivos a la arqueología. Su director fue José Palacios, un joven de ideales románticos y liberales. Otro periódico de importancia fue El Heraldo, que promocionó la idea de progreso y el apoyo a la industria siderúrgica. Tamayo afirma que fue el primero en citar a Proudhom, a Saint Simon y en hacer referencias al marxismo, impresionado por la revolución de 1848 en Francia.

Entre los libros destacan Viaje de Cuzco a Belén en el Gran Pará de Manuel Valdés, publicado en 1846, y la publicación en Lima de la primera novela peruana El Padre Horán (1848) del cuzqueño Narciso Aréstegui, coronel del ejército. Esta novela dio a conocer la miseria generalizada que asolaba al Cuzco durante los años 40, así como dio cuenta de la crisis que afectó a los artesanos de los obrajes, a los agricultores de pequeñas y medianas propiedades, describiendo las profundas desigualdades entre mistis enriquecidos y la mísera situación de la mayoría de la población runa. En 1876, se publicó El Recreo fundado y dirigido - como ya lo mencionamos - por Clorinda Matto de Turner.

\section{Clorinda Matto de Turner y el periodismo}

Clorinda Matto $^{2}$ comenzó publicando en el periódico escolar, continuó en $E l$ Heraldo, El Mercurio, El ferrocarril y El Eco de los Andes. Abelardo Gamarra (1890) afirma que empleó varios seudónimos, tales como Mary, Rosario, Adelfa, Lucrecia.

En 1871 se casó con el británico John Turner, quien se dedicó al comercio de productos importados y a la venta de lana. Fue representante de los señores Jorge Stafford y de la Compañía del Comercio de Arequipa y contaba con un molino y una casa en Tinta, lugar donde residieron durante diez años. Es allí donde la joven narradora conoció de cerca los mecanismos de enganche y explotación para el acopio de lana, lo cual relata es su primera novela Aves sin nido (Ortiz, 1993). 
Su primera experiencia en el arte de escribir como redactora y directora fue en 1876, cuando fundó El Recreo. A partir de entonces fue incursionando en una sociedad profundamente elitista y patriarcal, lo que le costó improperios, persecución y más tarde la destrucción de su imprenta. El Recreo fue el primer semanario de literatura, artes y ciencia en Cuzco dirigido por una mujer. Su experiencia vital, su padre y amistades más cercanas fueron sus principales impulsores.

El Recreo se publicó a partir del 8 de febrero de 1876 hasta enero de 1877. En esa revista dio a conocer sus primeras tradiciones y leyendas. También colaboró en los diarios La Prensa, La Nación y La Arbolada. En 1874, Carolina Freyre de Jaimes fundó El Álbum de Lima, mientras que Juana Manuela Gorriti y el poeta Numa Pompilio Yona crearon el periódico La Alborada de Lima.

En 1884, Matto de Turner dirigió el diario La Bolsa de Arequipa y, en Lima, el semanario literario y comercial El Perú Ilustrado, de octubre de 1889 a julio de 1890. En este se publicaron artículos que censuraron la Iglesia y las instituciones del Estado (Ortiz, 1993). En realidad, fue el pretexto para acallar el arrojo de una mujer que se atrevió a reflexionar en la tribuna pública sobre los problemas del país; para ello no necesitó ocultar su identidad (ponerse un nombre de varón como lo hicieron varias mujeres en Europa), lo que significó transgredir lo establecido. Para el orden social patriarcal, las mujeres debían mantenerse silentes y sumisas.

En febrero de 1892 abrió la imprenta "La Equitativa", ubicada en la calle Desamparados número 19. En 1893, fundó el semanario Los Andes, de tendencia cacerista, donde dejó ver que compartía con Cáceres su ideario de "peruanizar el Perú”. En 1895 triunfó Piérola: sus seguidores saquearon la imprenta, los Matto salvaron la vida. La periodista y narradora se vio obligada a abandonar el país. El 25 de abril de 1896 partió a Buenos Aires. En esta ciudad fundó El Búcaro Americano, una revista eventual de carácter literario. Colaboró en varios diarios e incentivó los propósitos del Consejo Nacional de Mujeres de la República Argentina y de la Asociación "Pro Patria", dio clases en la Escuela Comercial de Mujeres y en la Escuela Normal de Buenos Aires. 
En 1901, tradujo al quechua, para la Sociedad Bíblica - institución protestante-, el Evangelio de San Lucas, de San Juan y algunas epístolas de San Pablo; en 1903, el de San Marcos y en 1905 el de San Mateo. Consideraba que su traducción permitiría brindar un rayo de luz evangélica a 3.500.000 indígenas, así lo afirma el director de la Sociedad Bíblica en Argentina A. M. Milne (1901).

Durante aproximadamente 40 años, de 1870 a 1909, se dedicó al periodismo y a la literatura. Para ella, el periodismo constituía una tarea pedagógica que debía contribuir a despertar la conciencia cívica, con las consiguientes virtudes morales y el compromiso con el país, por eso debía ejercerse con libertad y honestidad.

En El Perú ilustrado y en Tradiciones, biografías y hojas sueltas se dirigió a los periodistas a fin de motivarlos de “[...] ir por todo el mundo, enseñad y predicad [...] la libertad de imprenta debe curar las heridas abiertas [...] y también predicar por doquiera la moral y las virtudes cívicas. El periodismo se ha vendido para callar, y enarbola la religión para propagar la cizaña” (Ortiz, 1993, p. 68).

Al revisar El Perú Ilustrado se aprecia su inquietud por dar a conocer la biografía de peruanos y americanos ilustres con el objeto de mostrar prácticas honestas y creativas, labor que comenzó con la biografía de Juan Espinoza Medrano. Llama la atención la variada publicidad de pequeños y medianos comerciantes, de importadoras, nacientes industrias que sostenían la publicación. En la visión de Matto de Turner, los males del país eran morales y económicos, la Guera del Pacífico puso al descubierto las profundas heridas generadas por quienes se habían dedicado a expoliar al país desde la llegada de Pizarro. Pero, desde su visión, había hombres valiosos como Manuel Pardo.

El quehacer periodístico y literario en el Perú fueron los primeros oficios que con cierta autonomía pudieron ejercer algunas mujeres de los sectores medios y altos. El hecho de practicarlos era un símbolo de subversión, como lo manifestó en una conferencia en el Ateneo de Buenos Aires, que tituló "Las obreras del Pensamiento" (Matto de Turner, 1902). 


\section{El semanario El Recreo}

El Recreo nació a iniciativa de Clorinda Matto. Abraham Vizcarra la acompañó en la dirección hasta el noveno número y se mantuvo como colaborador. A partir del N. ${ }^{\circ}$ 10, asumió la dirección Ricardo Villa ${ }^{3}$.

Matto de Turner logró la colaboración de importantes intelectuales de la época, Ricardo Palma ${ }^{4}$, Juana Manuela Gorriti, Trinidad Enríquez Ladrón de Guevara, Mercedes Cabello, Carolina Freyre de Jaimes, Francisca J. Necochea y su padre Ramón Matto, de gran influencia en su vida ${ }^{5}$. ¿Qué la impulsó a su creación? ¿Cuál fue el debate en torno al periodismo y la educación? ¿Por qué delegó la sección "Mosaico" a Trinidad Enríquez y no a otra persona? ¿Por qué Enríquez renunció intempestivamente? ¿Qué conflictos se produjeron? Son algunas de las interrogantes que intentaré responder.

El semanario fue publicado con el propósito de ofrecer un periodismo alternativo abierto a los intereses sociales. En "Prospecto", texto introductorio firmado por los directores (Matto y Vizcarra), se cuestiona que la prensa esté dedicada a defender los intereses políticos de los grupos de poder económico, que las condiciones de vida en Cuzco empeoren cada vez más, que se pierda la riqueza de su patrimonio cultural. El Recreo ofreció sus páginas a todos los creadores, en tanto consideraron que la tierra cuzqueña ofrecía muchas posibilidades creativas a través del encanto de su geografía y la riqueza de su tradición cultural. Estimaron que la literatura en su acepción de arte, ciencia y conocimiento debía estar al servicio de los pueblos, pero no como un esfuerzo individual y aislado sino colectivo; se propusieron facilitar la publicación y difusión de la literatura de la región, por lo que invitaron a colaborar a todas las voluntades amantes de la "cooperación y del progreso"; así, desde su visión el periodismo debía contribuir a la formación cultural y al desarrollo de las facultades de los seres humanos, incentivando la "perfección del genio", porque la calidad del periodismo es el termómetro que mide el grado cultural de un pueblo.

Clorinda Matto inauguró el semanario con un artículo dedicado a Francisca Zubiaga de Gamarra y a Juana Manuela Gorriti. Zubiaga rompió con los 
estereotipos femeninos de la época, pues mostraba cualidades consideradas masculinas: fortaleza, donaire, coraje y valentía; era capaz de tomar decisiones trascendentes, montar perfectamente el caballo y dominaba el uso de las armas de fuego. Para ser escuchada, no dudó en vestirse de varón; fue además anticlerical, postura que definió también a Juana Manuela Gorriti.

Los propósitos quedan muy claros en este primer número de El Recreo: ofrecer una prensa alternativa abierta a toda creación literaria, principalmente cuzqueña, pero también de otros lugares del país; ofrecer una tribuna a las mujeres que escriben; defender y fomentar la educación de las mujeres y de toda la población, teniendo como norte el obrar individualmente en una relación conjunta que conduzca al progreso. Pero no todos los colaboradores pensaban igual, así, al leer las diversas secciones del semanario se aprecian diversas posiciones. Las más conservadoras reproducen en sus textos los estereotipos de la clasificación de género dominante. Trinidad Enríquez, Juana Manuela Gorriti, Mercedes Cabello, Clorinda Matto estaban en minoría y ellas lo sabían, contaban con el apoyo solo de algunos varones, pero se trató de luchar contra la corriente en la propia boca del lobo.

Trinidad Enríquez, una de las voces más efervescentes de la época, aceptó el encargo de Clorinda Matto de reemplazarla a partir del tercer número en su columna "Mosaico", durante el tiempo que tuviese que atender las urgencias familiares; empero, se retiró intempestivamente a partir del sexto número. ¿A qué obedeció su renuncia? Antes es necesario conocer cuáles fueron los puntos de vista que se difundieron en el debate en torno al periodismo y la educación.

\section{"Si la imprenta es un poderoso elemento civilizador, su abuso es una verda- dera gangrena social"}

Ramón Matto, padre de Clorinda, en su artículo "Abuso de la imprenta", publicado en el primer número, plantea el dilema de los usos y abusos del "ingenioso invento de Gutenberg"; este puede contribuir al "perfeccionamiento racional" y mejoramiento de la condición humana cuando conduce con la verdad al "progreso", pero no cuando sus historias se nutren de intereses mezquinos y se usa la 
imprenta para su propio beneficio. En la historia de los partidos y la política, la prensa ha levantado caudillos que intentan destruirse unos a otros o que se elogian absurdamente. En estos casos se prostituye la palabra: "[...] ¿qué diremos de esos escritores insultadores que por la paga son capaces de escribir contra sí mismos?" (1876, p. 6).

En cambio, las redactoras y los solidarios redactores de El Recreo se propusieron defender un periodismo al servicio de los intereses de la mayoría de la población; uno de ellos fue el de la educación, reivindicado férreamente por Trinidad Enríquez, Clorinda Matto y Mercedes Cabello.

En "Errores tipográficos", el mismo autor plantea con gracia las dificultades en los procesos de edición. Sobre todo porque los que se ocupan de esta tarea no tienen un conocimiento adecuado de la escritura, los errores son tan numerosos que finalmente constituyen otra creación. Concluye con una breve anécdota en la que ironiza la ignorancia de los militares, cuenta que a un jefe militar se le ocurrió acabar con esos errores por decreto: "Ustedes pondrán los puntos, las comas y demás minuciocidades donde quieran; pero les prevengo, no sean ni mui francos, ni muy mezquinos con ellas, i en seguida con gran aplomo i garbo militar añadió: que haya verdadera economía ortográfica!" (sic), de tal modo que el título del artículo se podría haber transformado en "Horrores ortográficos" (R. Matto, 1876a, p. 13).

Es perentorio precisar que no solo faltaba el conocimiento ortográfico y el hábito de lectura, sino que la ciudad letrada era muy reducida. La población en su mayoría no sabía leer ni escribir.

\section{El derecho a la educación pública de las mujeres, un arma poderosa para resolver los problemas del país}

Trinidad Enríquez reemplazó a Clorinda Matto en la sección "Mosaico" a partir del tercer número. ¿Por qué la convoca a ella y no a otra persona? Según los datos biográficos reconstruidos sobre todo a partir de las referencias encontradas en la producción literaria de la narradora, comprendemos que fue su maestra más 
admirada en el Colegio Nacional de Educandas cuando cursó estudios entre los once y quince años, aproximadamente. En aquel entonces, en el centro escolar dirigido por Antonina Pérez, se buscaba que la formación convirtiera a las alumnas en maestras, ampliando de este modo el efecto pedagógico y alfabetizador según las pautas dadas por el ideario lancasteriano introducido por James Thompson a través de Bolívar cuando dispuso la creación de estos centros de instrucción. Trinidad Enríquez fue maestra y tuvo como alumna a la niña Clorinda. Es posible que en el colegio se haya usado la Biblia de origen protestante, publicada por la Sociedad Bíblica Británica. Thompson se encargó de su difusión, insistió en el conocimiento del Nuevo Testamento y en promover una moral ligada al progreso y al fomento de la industria. Principios en los que insistieron Antonina Pérez y las dos jóvenes redactoras del semanario.

Los cursos impartidos fueron música, aritmética, costura, gramática, urbanidad y geometría. El último estuvo a cargo de María Trinidad Enríquez que fue la primera mujer, que en el Perú, según referencias de Clorinda Matto, logró conquistar su ingreso a la Universidad Nacional de San Antonio Abad para estudiar jurisprudencia en 1875. Fundó la primera Escuela de Artesanos de Cuzco y participó en la creación de la Sociedad de Artesanos. Propició que el carpintero Francisco Morales postulará a una diputación, solicitud que no fue admitida, siendo ello un aliciente para que decidiese estudiar la profesión indicada. Trinidad Enríquez sufrió hostilidad por su aguerrida defensa de la educación de las mujeres y afrontó la persecución del "mal clero". En Leyendas y recortes, su pupila expresa su aprecio a este "cuerpo delicado casi infantil y de espíritu superior" (Matto, 1893, p. 167). Estas referencias permiten comprender el porqué delega su columna a su admirada maestra: apreciaba su tenacidad y brío.

Enríquez, desde su primera participación como redactora de la sección "Mosaico", sostuvo — con excelente prosa—, que su misión era enarbolar la educación de las mujeres; que podía referirse al clima, a las lluvias, al mercado y sus precios, a la "inexactitud de los sirvientes" (1876, p. 24), a las enfermedades, los impuestos, al comercio, las drogas de la botica o de la vida privada, a las calum- 
nias, el chisme, la oscuridad y la suciedad de las calles o a la administración de justicia, al "sopor de los encargados del bien público" (1876, p. 24), a la crisis monetaria o hablar de la corrida de toros, de la carencia de espacios públicos, de inacabados problemas; no obstante, lo más significativo e imprescindible, desde su visión, era combatir la peligrosa disposición de clausurar la antigua universidad a la que ella también asistía. La consideró una gran amenaza para la juventud, porque para ella la educación constituía la mejor arma para afrontar los problemas existentes. Por eso, el segundo problema planteado en este número fue el abandono en que se encontraba la escuela primaria, reclamó su urgentísima atención, a fin de evitar que cundiese la ignorancia.

Gracias a la decidida movilización de la población de todos los sectores sociales, se logró evitar la clausura de la universidad. Los más conservadores no lo esperaban. El malestar contra Enríquez se acentuó porque ya era conocida y temida por su firmeza, recordemos su lucha por lograr su ingreso a la universidad y su iniciativa de crear escuelas para los artesanos. Enríquez fue una de las más férreas impulsoras de la educación de las mujeres. Para los grupos de poder, la educación de las mujeres constituía un riesgo que podía perturbar sus privilegios, avalado por el orden sociosimbólico patriarcal encarnado en las instituciones.

\section{El amor al saber y el proyecto nacional}

Trinidad Enríquez propició la publicación del discurso de apertura de clases del rector don Manuel Antonio Zárate, pronunciado el 20 de febrero de 1876, por su notable defensa de la universidad, con una lógica distinta a nuestros tiempos, en tanto destacaba el amor al conocimiento. En tal sentido, distinguió a las personas que aman el saber de las que no lo $\operatorname{aman}^{6}$. Los amantes del saber tienen una actitud muy distinta: celebran la inauguración del año académico; en cambio, los segundos propician la violencia, los combates sangrientos, la vanidad en la política, la clausura de la universidad. A los que aman el saber les interesa la investigación, la difusión de sus resultados, la búsqueda del bien, de la belleza y la verdad. En cambio, el escaso interés por la educación contribuye a acrecentar el autoritarismo. Por eso, fue muy significativo y esperanzador que la población se pronunciase en 
contra del proyecto de clausura de la universidad; anunció una tendencia distinta en el país, que reafirmaba el convencimiento de que la búsqueda de bienestar no solo debía ser física sino también mental. La educación merecía ocupar el primer lugar en las instituciones, porque "una de las mayores facultades del ser humano es la razón y ésta se eleva mediante la educación" (1876, p. 23). Pero la inteligencia, la sabiduría sin corazón no es suficiente para conducir a los seres humanos y a la sociedad; la inteligencia sin el amor por el saber y la generosidad es un riesgo, en tanto puede conducir a la opresión y destrucción.

La instrucción fecunda, para el expositor influenciado por las ideas liberales y el positivismo, constituía la base del progreso. Solo a través de ella sería posible la riqueza y la perfección. Los gobernantes debían responsabilizarse del mantenimiento de los colegios y las universidades en las áreas que comprendía la enseñanza en aquel entonces - la teología, la filosofía, la jurisprudencia y la medicina-, porque la formación de hombres libres contribuiría a desarrollar un mejor gobierno. La instrucción debía alcanzar a todos por igual; dado que "los hombres son iguales ante la ley", la sola primaria no era suficiente. En cincuenta años de independencia no se había dado la debida importancia a la instrucción, no contaban con un plan de estudios, “[...] no hai un código común, que reúna los principios generales i las reglas más comunes, que tiendan á uniformar la instrucción pública en la Nación” (Zárate, 1876, p. 23).

Para el Rector, la educación requería constituirse en la base de un proyecto nacional. Así, planteó que la educación primaria no dependiese de los municipios; que la población necesitaba de una política de gobierno en el terreno educativo, sobre todo de la universidad, porque las materias que se impartían en ella no tenían planificación alguna; esta debía, entonces, organizarse de acuerdo a las diferencias territoriales. Zárate apreciaba la influencia del racionalismo, pero al mismo tiempo percibía su incompletud sin la espiritualidad, la generosidad y la materialidad territorial tan heterogénea. El plan nacional de educación debía contener principios generales de igualdad para toda la población, pero diferentes según el factor territorial. 
Trinidad Enríquez, en su segunda colaboración, sintetizó los acontecimientos ocurridos en la semana y con alegría elocuente celebró la inauguración del año académico universitario. La movilización de la población y de la propia Trinidad Enríquez logró impedir la clausura del claustro académico. Con intensa emoción realzó la presencia de la juventud, de la Sociedad de Artesanos, del "bello sexo", así como que todas las clases sociales hayan expresado un claro manifiesto y sentir republicano. En segundo lugar, vale mencionar la solidaridad de un sector de la prensa, en particular de los colaboradores de El Recreo, El Ferrocarril, El Inca y El Pueblo. En tercer lugar, se aprecia que surgen las primeras investigaciones referentes a la libertad de expresión, entre ellas, la tesis realizada por el señor D. Mauricio Luna para optar el bachillerato en la Facultad de Jurisprudencia, sustentada satisfactoriamente con el título: "La censura previa i la iresponsabilidad atacan la libertad de imprenta" (Enríquez, 1876a, p. 32).

\section{Sociabilidad, mujeres y espacios públicos}

Otro aspecto a considerar es su interés por promover la participación de las mujeres en los espacios públicos. En el Perú se había avanzado muy poco, en cambio en Argentina se sentía su presencia pública. Expresa su reconocimiento a María Eugenia Echenique - que el 9 de julio de 1875, en la sesión literaria que tuvo lugar en el Club Social de Córdoba de la República Argentina-, con ejemplar arrojo leyó un fervoroso discurso referente a la libertad de cultos, la libertad de expresión, la libertad civil, la libertad política y la libertad de religión. Para Enríquez la "regeneración de la mujer" (1876, p. 24) ya no era una utopía.

Por otro lado, Clorinda Matto recibió numerosos saludos por la fundación de El Recreo. Entre ellos destaca el de Abel A. Luna (1876, p. 38), que realza el esfuerzo de las mujeres en la escena pública a través de novedosas publicaciones dirigidas por ellas, tales como El Álbum y La Alborada de Lima. De sus hermanas cuzqueñas, celebra la imaginación, la fe, el corazón y dedicación que le ponen.

Es destacable el apoyo de colaboradores hombres, entre ellos Felipe Paredes, por cuanto defiende la democratización de los espacios públicos. En su artículo dedicado a la sociabilidad, precisa que una sociedad cerrada y sin comunica- 
ción, que no ofrece centros de reunión o espacios públicos para compartir, dialogar y debatir, atenta contra la formación del ser humano; por consiguiente, no puede formarse a las niñas de esa manera, se trata de que las niñas vivan en sociabilidad y no recluidas. El autor apunta a la necesidad de abrir espacios que estimulen “fuegos de imaginación y sensibilidad” sin discriminación de género (1876, p. 37).

En el artículo "La educación de la mujer", Francisca J. Necochea (1876) defiende la educación integral de las mujeres, ya que están dotadas de iguales facultades que los hombres. Ambos asumen responsabilidades, ellos cumplen el rol de formular las leyes y las mujeres las costumbres, en tanto es la encargada de formar a los niños y de brindar las primeras expresiones de cuidado, ternura y lealtad. La mujer como el varón es capaz de todo, incluso de lo heroico; puede ser fuente de bienestar o malestar, de prosperidad o decadencia, todo depende de la educación que reciba. Preferir solo la educación del hombre deja incompleta la formación de la humanidad. Para Necochea no bastaba cuestionar las relaciones de dominación entre señores y esclavos, entre opresores y oprimidos, había que terminar con la degradante situación de "servidumbre de la mujer más humillante que la del esclavo". La "divina luz del Evangelio" debería extenderse a todas las mujeres, a fin de lograr el progreso y la civilización, lo que sería posible solo con la instrucción pública.

En su tercer mensaje, Trinidad Enríquez se sitúa desde un sentir y mirada cósmica en movimiento, asentada en un territorio específico, el Cuzco: “iQué bello es viajar sin sentirlo! [...] Nuestra humilde Tierra, ese grano de arena en el espacio, se hace un tanto perezosa porque vá á su apelio; haciendo tomar a sus habitantes la deliciosa temperatura média" $(1876$, p. 40). Si bien en tierra cuzqueña no se sienten las cuatro estaciones, sabe que los labradores celebran la cosecha, y ella con ellos, agradeciendo los dones de la Naturaleza, cuando en otros espacios se celebra la primavera. Agradece la invitación de la sociedad "Colaboradores del Progreso" para suscribirse a El Siglo. Por último, felicita al Dr. Rafael Paredes por su respuesta a los padres del Liceo de Párvulos, a fin de que confiasen en la misión que tienen de formar a los niños teniendo presente las máximas evangélicas. 


\section{La renuncia de Trinidad Enríquez: conflictos internos y públicos, autorita- rismo y democracia}

En el N. ${ }^{\circ} 6$, del jueves 6 de abril de 1876, se publicaron artículos que expresan los conflictos internos entre los propios colaboradores del semanario y la crítica de los lectores. Unos apoyaban la presencia de las mujeres en los espacios públicos y otros reprobaban o ridiculizaban su participación creativa. En tal sentido, se distinguen posiciones tanto autoritarias como democráticas.

En el artículo que inaugura el semanario, denominado "Gratitud", los directores agradecían los saludos y cumplidos recibidos; precisaron que el periodismo está sembrado de abrojos y de flores, de hondas alegrías y amarguras, pidiendo a sus lectores que los excusen de los defectos que la publicación pueda tener, que comprendan que es "el primer paso de un grupo de mujeres que promete ponerse a la vanguardia de la civilización" (Directores, 1876, p. 41). Frases que dan cuenta de las críticas recibidas. Ante estas, en el artículo titulado "Amistad", firmado por María, se destaca la importancia del respeto, principio que no debe perderse en ninguna circunstancia.

En cambio en "Asuntos varios o taracea", publicado a manera de folletín por entregas y sin firma en este número (1876, p. 46), si bien empieza explicando los significados de taracea y mosaico, el objetivo es otro. Taracea es una acepción genérica referente al proceso artesanal de incrustación que comprende al mosaico, por lo que existe una pequeña diferencia entre los dos. El mosaico puede incrustar piedras preciosas sobre mármol u otros materiales. Pero el objetivo no es aclarar esta diferencia, sino de atacar y recusar a la redactora de la columna "Mosaico".

La crítica recibida se centra en ella, en Trinidad Enríquez pero sin mencionar su nombre. El mosaico periodístico debía ocuparse de la crónica de sucesos llamativos pero intrascendentes, tales como el "lado" débil del mariscal don Ramón Castilla, a quien supuestamente le angustiaba la vejez; la niña que parecía mayor o tal vez referirse a uno que otro "caso raro" o que al doctor don Manuel Torres y Matto le hayan "obsequiado" un muchacho de la provincia de Paruro, 
con unas características físicas muy cercanas al oso. Lo que además implica una visión racista y de intercambio de seres humanos convertidos en objetos raros.

La redactora de "Mosaico", por ser mujer, debía ocuparse de cuestiones nimias o baladíes, no tenía sentido que escribiese sobre ciencia o educación ni que diera a conocer la realidad de otros países y menos de escribir exigiendo el derecho a la educación de las mujeres y de la población en general.

En la nota denominada "Pensamientos", firmada por Hurías, con fecha de marzo de 1876, se aprecia la visión sexista que encarna a quien escribe y su visión conservadora; la razón y la virtud son faros exclusivos del hombre, la primera enseñaría la verdad, la segunda el mal; por consiguiente, entre las revueltas y malos gobiernos, lo mejor era optar por la continuación y alejarse de todo cambio. Un segundo tema es el matrimonio, en el que se clasifica el sentir de las parejas por su género con respeto al matrimonio. De mil mujeres casadas diez están arrepentidas; en cambio, de mil casados hay solo diez contentos. La mujer es feliz de estar casada, el hombre de soltero. "La mujer en sus 15 abriles finge no querer el matrimonio [...] en sus 20 tiene envidia de los que se casan; a las 25 años en público aboga por el celibato, á solas llora, se estira y ruega adiós por un marido; a los 30 viste luto y se queda de tía á vestir santos o de redactora" $(1876$, p. 48).

En esta clasificación, los varones son los que gozan y disfrutan su independencia, en cambio las mujeres asumen la exigencia del deber ser. Ser bellas y casaderas en honor de su absoluta dependencia, porque de lo contrario, corrían el riesgo de no poder vivir con holgura y, siendo el transcurso del tiempo inevitable, se podían quedar solteras o convertirse en subversivas redactoras. Hurías, seudónimo del autor de la nota, apuesta no por el cambio de esta larguísima, sexista y estereotipada visión sino por su continuidad. Aunque, contradictoriamente aboga por la educación (sin especificar el sexo/género), ya que desde su perspectiva la cultura de un pueblo se conoce a partir de cómo están organizados sus colegios y universidades y no por sus monumentos y leyes escritas. Las críticas y defensas en varios casos fueron firmadas con seudónimos. 
La respuesta de Trinidad Enríquez no se dejó esperar. En este mismo número, en su última colaboración, expresó con profundo malestar su rechazo a la censura y la violencia, su condena a los estereotipos, su resistencia a sujetarse a los designios del orden social y su defensa de la libertad de expresión y de los derechos civiles. Sostuvo que la escritora y redactora pública no puede sujetarse a un orden social opresivo. La misión de la escritora pública no puede ejercerse sin libertad de expresión. Enríquez se despide ironizando a la crítica autoritaria:

Mis amables lectores no sabiendo cómo dar principio a este humilde mosaico me preocupe tanto de el, que llegue ha confundirlo con la crónica y hasta me olvide si debía escribir con zeta o con ese (por qué debo advertiros que no entiendo bien ortografía) para salir pues el paso tuve que acudir al diccionario, desde que no tenía quien confiar mis duda s [...]. Pero perdónenme UU. soy tan ignorante, que lejos de cumplir mi intento, fui há divagar en dorados, purpurinos, arrebolados, nacarados, vespertinos, ageografados ensueños.

¡Por Santa Bárbara!

¿No comprender que soy cronista de "El Recreo" y ocuparme de Lima, de París, de San Petersburgo y otros países.

¿Han visto U.U. estravagancia semejante?

Pero por más que me suplican sinceramente y me censuran concienzudamente, no podré llegar ha desempeñar perfectamente mi misión.

¿Sabéis de qué misión se trata?

Nada menos que el de escritora pública.

Yo que me descuido en el fondo y en ortografía de mis mal trazados escritos ocupándome de las capitales de Europa y de mis ensueños.

Porque si se trata de la crónica del Cusco [...] sólo tenemos grados, defunciones, matrimonios. Por que al ocuparnos de los intereses del país, tememos herir más de una susceptibilidad. Ahora descender al terreno de las personalidades, so pretexto de crónica u otro epígrafe como lo hacen para mengua del país, algunos de nuestros periódicos, sería ofenderos y muy ajeno de nuestro carácter. (1876c, p. 48)

Concluye su intervención comentando el artículo del doctor Augusto de Escudero en El Correo del Perú. Comparte su critica al clero por la compra y venta de sacramentos que incrementan su riqueza, mientras que los que no tienen 
para pagarlos se encuentran sujetos a su disposición. La autora recomienda su lectura porque concuerda con él en la necesidad de emancipar las conciencias del pueblo.

La crítica de la ciudad letrada, sobre todo masculina, que se siente amenazada y temerosa por el despertar de las mujeres, la increpa de ignorante: qué hace una mujer desinformada de redactora. Su ignorancia radicaría en la apropiación ilegal de la tribuna pública, en confundir la crónica con el mosaico, en no tener noción de ortografía, en divagar en ensueños, en no comprender que siendo cronista de El Recreo tendría que ocuparse exclusivamente de algunas anécdotas cuzqueñas y no de Lima ni interesarse en lo que ocurre en el mundo y menos en el saber ni la ciencia. El cultivo, la difusión y la producción de conocimiento de las mujeres constituía y constituye un gran peligro que atenta contra los privilegios de los grupos de poder.

Enríquez invoca a Santa Bárbara, asocia el martirio sufrido por la joven con las agresiones que sufren las mujeres que resisten la opresión y luchan por su emancipación. Bárbara fue una bella princesa de Oriente, no griega — por eso el nombre-, a quien su padre encerró para evitar que se acercasen pretendientes gamberros. La joven se hizo conversa, sufrió torturas hasta que finalmente fue decapitada. Trinidad Enríquez se sintió muy afectada y renunció, pero no declinó; armada de valor prosiguió afrontando los abrojos del camino con el apoyo de Mercedes Cabello, Juana Manuela Gorriti, entre muchas más.

\section{Mercedes Cabello}

Mercedes Cabello fue también una colaboradora destacada de El Recreo. En su artículo titulado: "Progreso" sostuvo que el anhelo de prosperar constituye la "expresión mas bella y grandiosa de la inteligencia humana". El progreso suponía avance y novedad, el descubrimiento de nuevos conocimientos y horizontes. No se reduce al cálculo y crecimiento económico. Si sus padres antiguamente vieron las estrellas como luces o linternas, en el luminoso presente de fines del siglo XIX se descubrió que eran otros mundos que ruedan en el espacio inconmensurable, 
porque todo movimiento es progresivo y también lo es la propia humanidad: "La ley del progreso es la del movimiento; vivir para el hombre debe ser progresar" (1876, p. 77). Ello presuponía confiar en la razón, considerada la mayor facultad humana; en tal sentido, la idea de progresar simbolizaba "todos los sentimientos más nobles y elevadas del corazón humano" (1876, p. 77).

La verdadera revolución, fuente de progreso, para Cabello de Carbonera en esta primera etapa como redactora pública era la educación social de la mujer, en tanto la lucha de las mujeres era parte de la lucha del progreso contra el oscurantismo, "de la verdad con el error, de la luz con las tinieblas". La demanda de instruir y emancipar a la mujer era blanco de sátiras, por eso recurre a Víctor Hugo, quien sostuvo que si el siglo XVIII fue el siglo del hombre, el siglo XIX sería el de la mujer, "la igualdad de las mujeres forma parte de la igualdad de los hombres" (Cabello, 1876, p. 195).

\section{Coda}

En el siglo XIX, el periodismo fue la principal tribuna de opinión. Los conservadores y grupos de poder temían que estuviese en manos de mujeres, lo cual agravó la desconfianza: podían perder sus privilegios y poder.

Los quehaceres periodístico y literario fueron los primeros oficios que con cierta autonomía pudieron ejercer algunas mujeres de los sectores medios y altos. El hecho de practicarlos constituyó una subversión, por cuanto empezaron a apropiarse de la tribuna pública.

Las mujeres periodistas de fines del siglo XIX afrontaron calumnias, censura, improperios cotidianos y grandes retos. La suma de sus experiencias vitales, la formación recibida, su indagación intelectual, las nacientes ideas vinculadas a la fe en el progreso canalizaron sus esperanzas y las impulsó a resistir, a combatir y a proponer alternativas.

Entre las jóvenes periodistas de El Recreo se percibe el aprecio a George Sand, a Fernán Caballero — seudónimo de la escritora española Cecilia Böhl 
de Faber-, quien se interesó por el costumbrismo y la defensa del catolicismo vinculado al bien y a la virtud. Las redactoras públicas de El Recreo atacaron al periodismo que se vende y calla, a los grupos de poder socioeconómico y patriarcal que impedían la ilustración de las mujeres.

Las escritoras públicas combatieron al orden social opresivo, defendieron la libertad de expresión y los derechos civiles. Respondieron y atacaron al sector de la Iglesia que las hostilizó y censuró. Con todo, consideraron que la fe en el progreso y la fe religiosa debían ir juntas en la formación de la mujer por cuanto ella como madre era la encargada de dar pautas de comportamiento ético, la primera en brindar a las niñas y niños las expresiones iniciales de cuidado, afecto y lealtad.

$\mathrm{Su}$ objetivo fue ofrecer una prensa alternativa abierta a toda creación prioritariamente cuzqueña. Estimaron que el periodismo y la literatura entendida como arte, ciencia y conocimiento debían estar al servicio de los pueblos, pero no como un esfuerzo exclusivamente individual, sino cooperativo y en ese sentir demandaron la educación pública de las mujeres y de toda la población bajo el principio de la igualdad. Afrontaron la crítica autoritaria de quienes ridiculizaron su participación creativa en la tribuna pública.

En ese proceso tuvieron el apoyo de algunos intelectuales democráticos que como el rector Zárate propuso la necesidad de elaborar un plan nacional de educación que debía contener principios generales de igualdad, pero diferentes según el territorio; o de Paredes que sostuvo que las niñas necesitaban vivir en sociabilidad y no recluidas porque todo ser humano necesita ser estimulado a fin de despertar la imaginación y creatividad. Preferir solo la educación del hombre dejaba incompleta la formación de la humanidad.

Las redactoras públicas de El Recreo apostaron por un arte y pensar crítico pero sujeto aún al mandato sociocultural de la maternidad y al positivismo naciente. Se distinguieron por su firmeza de carácter, curiosidad y perseverancia, por su compromiso con los intereses de las mayorías del país. 
Su participación en la tribuna pública, les permitió ejercitarse en la escritura, en crear espacios de encuentro y debate entre ellas mismas y el público lector e ir construyendo una actitud de resistencia ciudadana y pensamiento críticos ante las opresivas y destructivas relaciones de dominación que fueron denunciadas en sus publicaciones posteriores.

\section{Notas}

1 En 1990, cuando inicié una investigación referente a la obra de Clorinda Matto, no logré ubicar la revista $E l$ Recreo, por eso mi agradecimiento a Horacio Cagni, historiador argentino, por enviarme una copia escaneada en PDF de la revista en su integridad el 16 de febrero de 2016. En su misiva manifiesta que al leer un artículo de mi autoría dedicado a Clorinda Matto en la revista Investigaciones Sociales de la UNMSM decidió enviarme el archivo. A su pedido, el archivo ha sido compartido con algunas instituciones y colegas. Esperamos que pueda ser publicado pronto de manera virtual, por ahora no cuenta con la nitidez necesaria. A nuestra pregunta de cómo la revista llegó a sus manos, recuerda que vio "desde siempre en la biblioteca de casa esa colección", que forma parte de lo heredado de su abuela materna, peruana de nacimiento, nacida en Arica antes de la Guerra del Pacífico, aproximadamente en 1874, y que con su familia emigró a Argentina. Clorinda Matto viajó a Buenos Aires el 25 de abril de 1896, después de que sufriera reiterada persecución, así como el saqueo y la destrucción de su imprenta. Es posible que se hayan conocido en esa ciudad.

2 Clorinda Grimanesa Martina Matto Usandivaras nació en Cuzco el 11 de noviembre de 1852, año en que se promulgó el primer Código Civil inspirado en el Código napoleónico de 1804. Era el gobierno de José Rufino Echenique, donde la aparente generosidad de una buena parte de los miembros de la Iglesia escondía sus privilegios y poder; ellos poseían las conciencias de la mayoría. Así, mientras que las autoritarias instituciones civiles y militares gozaban de supuestos designios divinos, se profesaba que unos habían nacido para mandar y otros para obedecer. Este es el mundo en que abrió los ojos Clorinda Grimanesa Martina Matto Usandivaras. Véase la tesis de Carolina Ortiz Fernández: Clorinda Matto de Turner. La censura y la fe. Modernidad, etnicidad y género (1993).

3 Matto de Turner le dio la bienvenida en la sección "Mosaico" el 14 de junio de 1876.

4 Ricardo Palma escribe una amorosa carta fechada el 26 de febrero de 1876 en la que agradece a Matto que le haya dedicado la tradición publicada en el primer número y la felicita por la atinada publicación y edición de la revista, instándola a escribir las tradiciones cuzqueñas.

5 Ramón Matto fue fundador de El cóndor de los Andes, redactor de El Sol del Cuzco y de El Instructor Popular. Fue alcalde del Cuzco dos veces. Al retirarse de la vida pública, se dedicó a la agricultura. Tomó el apellido materno de su padre, Matto en lugar de Torres, lo cual es un indicador de su reconocimiento a la abuela. Es posible que su relación con ella le haya infundido la valoración de la mujer que transmitió a sus hijos.

6 En los siglos XX y XXI, el amor al saber se ha venido a menos por la mercantilización de la educación. 


\section{Referencias bibliográficas}

Cabello de Carbonera, M. (1876). Perfeccionamiento de la educación y la condición social de la mujer. El Recreo. Cuzco, 20, 195-196.

Cabello de Carbonera, M. (1876a). "Progreso". El Recreo. Cuzco, 10, 77.

Directores. (1876). Gratitud. El Recreo. Cuzco, 6, 41.

Enríquez, T. (1876). Mosaico. El Recreo. Cuzco, 3, 24

Enríquez, T. (1876a). Mosaico. El Recreo. Cuzco, 4, 32.

Enríquez, T. (1876b). Mosaico. El Recreo. Cuzco, 5, 40.

Enríquez, T. (1876c). Mosaico. El Recreo. Cuzco, 6, 48.

Gamarra, A. (1890). “Apuntes de Viaje”. En Clorinda Matto de Turner. Bocetos de americanos célebres. Lima: Imprenta Bacigalupi.

Hurías. (1876). Pensamientos. El Recreo. Cuzco, 6, 48.

Luna, A. (1876). Albores y destellos. El Recreo. Cuzco, 1, 38.

María [seudónimo]. (1876). La Amistad. El Recreo. Cuzco, 3, 46.

Matto, R. (1876). Abuso de la imprenta. El Recreo. Cuzco, 1, 6.

Matto, R. (1876a). Errores tipográficos, El Recreo. Cuzco, 2, 13.

Matto de Turner, C. (1876-1877). Directora de El Recreo, Cuzco, 242.

Matto de Turner, C. (1893). Leyendas y recortes. Lima: La Equitativa.

Matto de Turner, C. (1902). Boreales, miniaturas y porcelanas. Buenos Aires, Imprenta de Juan Alcina.

Milne, A. M. (1901). El Estandarte Evangélico de Sudamérica. Buenos Aires, s.e.

Necochea, J. F. (1876). La educación de la mujer. El Recreo. Cuzco, 5, 35-36. 
Ortiz Fernández, C. (1993). Clorinda Matto de Turner: la censura y la fe. Modernidad, etnicidad y género (Tesis de licenciatura en Sociología). Universidad Nacional Mayor de San Marcos, Facultad de Ciencias Sociales, Lima, Perú.

Ortiz Fernández, C. (2008). Mujeres, Universidad y sociedad. Revista de Sociología, UNMSM, 18, 147-165.

Palma, R. (1876). Carta. El Recreo. Cuzco: 5.

Paredes, F. (1876). Conveniencias de la sociabilidad. El Recreo, Cuzco: 5, 33.

Porras Barrenechea, R. (1970). El periodismo en el Perú. Lima: Instituto Raúl Porras Barrenechea, UNMSM.

Tamayo, J. (1978). Historia social del Cuzco republicano. Lima: s. e.

Zárate, M. (1876). Discurso del Rector de la Universidad San Antonio de Abad, Dr. Manuel Antonio Zárate en la apertura del nuevo año escolar. El Recreo. Cuzco: 3, 22-23. 